experiment.--Dr. Svtcliffe (Stalybridge), from personal observation of cases, thought that the time had not yet arrived for formulating any definite rules as to the best method of using the lymph, or as to the results of its action. Probably the best way to treat phthisis would be by small doses injected at intervals of a fortnight spread over a long period of time, and conjoined with all hygienic, tonic, and climatic treatment available. Dr. Sutcliffe showed an asbestos syringe largely used in Berlin in preference to the one used by I) Koch.-Dr. BrierLey deprecated following a "method," and using a preparation the composition of which was not known to the profession, and was of opinion that English practitioners would be chary about putting this sensational treatment of tuberculosis into practice. Since the method was purely experimental at present, Dr. Brierley thought the treatment should only be carried out in hospitals where the patients could be constantly under the immediate care of skilled workers.-Dr. Simpson, though disliking the secrecy, at present perhaps unavoidable, of Koch's preparation, considered that they would not be justified in passing it by. Its use required great care and caution, and its curative value was not as yet firmly established. In many advanced cases, or where pulmonary tubercle was extensively distributed, it was contraindicated, and it could only be used with the utmost possible caution in any threatening of meningeal tubercle. Then, too, there was some evidence that it might set up activity in some cases where tubercle might have remained. This raised the question, what became of the bacilli? They did not share, it seemed, in the death of the tuberculous tissue. Were they in some cases, by the absorption of this, simply set free with their active properties unimpaired?-The Prnsinent and others also addressed the meeting.

\section{NOTES FROM BERLIN CLINICS.}

By T. STACEY WILSON, M.B., C.M., M.R.C.P., Assistant-Physician Birmingham General Hospital.

Variations in the Character of the Reaction.-Persistent Pyrexice treated by Larger Doses.-The Local Effects produced in the Lungs.

Is commection with the apparent uncertainty as to the amount of reaction that occurs in certain tuberculous cases, it is very important to recognise the fact that well-marked and even extreme internal reaction may occur where there is very little temperature reaction. This fact was strikingly brouglit out recently by Professor Leyden, who pointed out that a case of his which showed post mortem extraordinarily severe changes as a result of the new treatment had shown almost no signs of reaction, and the temperature lad not risen to $101^{\circ} \mathrm{F}$. until a dose of 5 centigrammes was given. This patient-a woman with advanced phthisis and amvloid disease -received in twelve days seven injections, and a total of 1 decigramme of the lymph. We see cases of a less severe nature when the tolerance is to all appearance real; and it is not unusual to meet with cases of chronic tuberculous phthisis, even with extensive cavities, where the dose can be raised as rapidly as in the above case, and with good result.

In contrast with these we sometimes see cases where the reaction is abnormally great, and the patient develops an intermittent pyrexia, as in advanced phthisis. Here we may find ourselves in a dilemma through not knowing whether the fever is due to a reaction produced by too large a dose of the remedy, or to the dose being too small to properly protect the system from the morbid substances produced by the disease or set free by the treatment. Sometimes the former seems to be the case, and the temperature subsides if the injections be omitted for a few days; but in other cases the latter seems to be the true explanation, and the temperature continues high at night until an injection sufficient to cause a very considerable reaction is given.

This question as to the amount of the dose is also of extreme importance when dealing with the hectic temperature of advanced phthisis. Are we in these cases to continue with small doses without increasing them until the temperature comes down? or are we boldly to push on to larger doses and high temperature reactions even to the limit which the patient's strength will allow? From the cases I have had the opportunity of watching, and from what I have been able to hear, I think that the last named is the best for the patient; but upon this as upon very many other points we can only be guided by the results of patiently gathered experience.

Two cases in Professor Leyden's wards illustrated this lastnamed mode of treatment. In one intermittent pyrexia contimued until a good reaction was obtained, and in the other pyrexia increased, if anything, with small doses, and became hectic in type; the patient, moreover, developed considerable pneumonia, with some fresh excavation of one lung. The dose was here increased from $0.0015 \mathrm{~g}$. on December $8 \mathrm{th}$, to $0.002 \mathrm{~g}$. on December 10th, and $0.005 \mathrm{~g}$. on December 12th, and on December 15 th $0.008 \mathrm{~g}$. was given, and this in spite of the rise during reaction reaching $104^{\circ} \mathrm{F}$., while the temperature never fell below $101^{\circ}$ or $102^{\circ}$, and on days when no injection was given reached $103^{\circ}$ or so at night. After the injection of 5 milligrammes, the morning temperature fell to $100^{\circ} \mathrm{F}$, the lowest for five days, and after the injection of 8 milligrammes to $99^{\circ} \mathrm{F}$. The most marked change was, however, in the pulse, which fell from 115 or 120 to 85 on December 15th, and 55 on December 18th, with an evening temperature of only $101^{\circ} \mathrm{F}$.- the lowest for fifteen days. Next day the pulse was 75 , and the temperature was rather higher again. Two days after the injection of 8 milliorammes, the patient was still feeling very low and ill, and dissatisfied with the treatment, but on December 19th was looking and feeling better.

With regard to these advanced cases, the feeling seems to be that the lowered vital powers which usually accompany a hectic temperature renders them more or less unsuitable for treatment. This is especially so with regard to the digestion, for if the patients have not good powers of assimilation, the increased tissue metamorphosis brought about by the remedy will seriously undermine their strength. Further, it is necessary to remember that the remedy itself seems to have some special action on the stomach, for abdominal pains are apt to be caused when there is no reason to suspect abdominal tuberculosis. Too much attention cannot be paid to the diet of patients undergoing the treatment, but especially to that of advanced cases where there is a possibility of gastric or intestinal tuberculosis, for under these circumstances it may happen that both stomach and intestine may be the seat of very extensive ulceration, in consequence, probably, of the sloughing of tuberculous tissue which the remedy has produced. Such a condition has been recently demonstrated in the post-mortem examination on one of Professor Leyden's cases which has already been referred to.

As to the nature of the local reaction that takes place in the lungs, there is much still to be learnt, for we have to draw our conclusions almost entirely from evidence of a clinical and not pathological character. In addition to the congestive changes which give rise to the copious watery expectoration so usually seen during the reaction, we can frequently observe the development of actual consolidation, which may be of considerable extent, from the action of the remedy. This may be, however, unaccompanied by any special rise in the temperature, and such was the case in several of the instances that came under my notice at Berlin. I did not hear any expression of opinion as to the prognostic significance of this inflammation, but in most of the cases referred to the physical signs of consolidation cleared up in a week or so, on continuance of the injections. It seems likely that it is of a similar nature to the inflammatory reaction seen in tubercular tissue elsewhere, and is the process by which the morbid tissue is destroyed. It is possible, however, that it may sometimes partake of the character of a true pneumonia.

There is, I think, no reason to doubt that degenerative processes take place in the lungs, and that the tubercular tissue disappears here as elsewhere by a process of exfoliation or absorption. The following points are in favour of this :-

1. The disappearance of consolidation and restoration of resonance and vesicular breathing which is observed in favourable cases.

2. That signs of fresh cavity formation are sometimes to be observed clinically. In one out of two fatal cases where I had an opportunity of seeing the lungs post mortem there were evidences of fresh cavity formation, although the changes were not sufficiently unusual in character to be put down with certainty as due to the remedy and not to the usual morbid 
processes. These two post-mortem examinations have been dealt with at some length in a paper by Dr. Jürgens in the Deutsche med. Wochenschr., but we shall await with much interest a fuller and more detailed account of the changes in the lungs. The systematic search for elastic fibres in the sputa may yield some evidence on this head, although it is by no means certain that they will be increased, since the remedy acts on the tubercles, not the lung tissue proper.

3. Bacilli frequently appear in the sputa for the first time within a few days of the commencement of the injections, or, if previously present, their number is increased at first. Later on the number again diminishes, and, in favourable cases, they disappear altogether. In these cases it seems probable that the bacilli are set free by the breaking down of the tissue containing them.

This seems the probable explanation of the sudden increase in the number of shrunken and broken bacilli which is often observed after the use of the remedy.

In the above remarks I have not dwelt much on the general effect of the remedy in suitable cases, but, before bringing these remarks to a close, I feel bound to say that it was impossible to go through the hospital wards at Berlin withou being impressed by the improvement that a very large proportion of the phthisical patients showed from the treatment they were undergoing.

\section{NOTES ON THE DILUTION OF DR. KOCH'S}

\section{LYMPH FOR TUBERCULOSIS.}

Mr. Henry Campbeld, Pharmaceutical Chemist, Queen's Hospital, Birmingham, writes :-

Dr. Koch's lymph for the treatment of tuberculosis is sent out in stoppered bottles, each containing 5 cubic centimètres. It is slightly viscid, and has a specific gravity of 1150 . It keeps well with ordinary care.

The dose for an adult ranges from 0.001 cubic centimetre to ten times that amount, 0.01 cubic centimètre. In some reports these quantities are called 1 milligramme and 10 milligrammes (or a centigramme) respectively. This is not strictly correct, for 0.001 cubic centimetre of the lymph weighs slightly more than a milligramme.

For hypodermic use the lymph is diluted, a 1 per cent. solution being usually the most convenient; but in some cases a stronger solution ( 10 per cent.), or a weaker $\left({ }_{1}^{1}\right.$ th per cent, or 1 in 1,000), is desirable.

If a dilution made with distilled water is to be set aside for a few days, it must first be raised to a boiling point-a process which Dr. Koch states is likely to weaken the lympl. It is better, therefore, to dilute with a $\frac{1}{2}$ per cent. solution of carbolic acid. If a dilution becomes turbid it is unfit for use.

All measuring apparatus and bottles used to prepare the dilutions should be rinsed with the carbolised water, drained and kept free from dust, and the hypodermic syringe washed with absolute alcohol, and then with the carbolic diluting fluid. Alcohol renders the stronger solutions slightly turbid.

To make the diluting fluid ( $\frac{1}{2}$ per cent. carbolic), place a pint of distilled water in a flask, marked at that volume, boil for five minutes, add 44 grains of pure carbolic acid, boil for another minute, cork up, and remove from the heat. When cold, dilute if necessary to one pint with boiled distilled water.

To make the dilutions (metrical system), attach an ordinary half-ounce glass syringe by india-rubber tubing to a pipette of 1 cubic centimetre capacity, and deliver half a cubic centimètre of lymph into a 10-cubic centimètre measure. Rinse the pipette twice with the diluting fluid, add the rinsings to the lymph and dilute the whole to 5 cubic centimètres. Place in a stoppered bottle, and label Dr. Koch's tubercle lymph (10 per (ent. solution, No. 1); 0.01 cubic centimètre of solution contains 0.001 cubic centimètre of lymph.

In the same way, dilute half a cubic centimètre of No. up to 5 cubic centimètres, and label (1 per cent. solution, No. 2$) ; 0.1$ cubic centimètre contains 0.001 cubic centimètre of lymph.

If required, dilute half a cubic centimètre of No. 2 up to 5 per cent. and label (one-tenth per cent. solution, No. 3); 1.0 cubic centimètre contains 0.001 cubic centimètre of lymph.

The special hypodermic syringe used by Dr. Koch contains (when filled to the mark nearest the india-rubber ball) 1 cubic centimètre, and is graduated into ten divisions. Therefore-

A syringeful of No. 1 dilution $=0.1$ cubic centimètre of lymph.

A syringeful of No. 2 dilution $=0.01$ cubic centimètre of lymph.

A syringeful of No. 3 dilution $=0.001$ cubic centimetre of lymph.

** The English measurements are not nearly so easily managed as those of the metrical system; and it would be well, in carrying out treatment and giving descriptions, to adhere to this latter, otherwise there would be endless confusion, especially where people have not the opportunity of, or practice in, translating one into the other.

CASES AT VICTORIA PARK HOSPITAL.

$W_{E}$ are requested to state that it is proposed to send to a convalescent home three of the patients now undergoing treatment by Professor Koch's method in Dr. Heron's wards in the City of London Hospital for Diseases of the Chest, Victoria Park, E., and that these patients may be seen at the hospital by medical men on Monday and Tuesday next, between 3.30 and 4 P.M.

BRISTOL GENERAL HOSPITAL.

Dr. Markham SkerritT and Dr. Barclay Baron, who recently visited Berlin as representatives of this institution, have received from that city two bottles of Koch's fluid, with which they have commenced treatment in the hospital.

DEVON AND EXETER HOSPITAL.

THE staff of the Devon and Exeter Hospital propose to demonstrate Dr. Koch's treatment at the Devon and Exeter Hospital on Wednesday, January 14th, at 10 A.M. Members of the profession in Exeter and neighbourhood wishing to attend may apply to the House-Surgeon for a ticket of admission.

GLASGOW.

Tue treatment of tubercle by Koch's method goes quietly forward in the Royal and Victoria Infirmaries of Glasgow. The only incident to be noted at present is the death of a patient, who had been an inmate of the Royal Infirmary, and had received one injection of 0.001 gramme, but who, in spite of the expostulations of physicians and nurses, insisted on going home on the second day after, where it has been learned he died two days later. He had been in hospital for seven weeks, and was being treated in the ordinary way. It was at his own urgent request that Koch's treatment was begun, after, of course, it had been decided by the staff that he was a suitable patient for it. Some amount of reaction occurred after the injection, and some hæmoptysis.

At the Western Infirmary the physicians have been put in possession of some of the coveted fluid, and arrangements will shortly be completed for observing its results.

\section{AUSTRIA.}

The Association of Medical Practitioners of the First I)istrict of Vienna at a recent meeting passed a resolution to the effect that it is highly desirable that Dr. Koch should, "in the interests of science and of suffering humanity," publish the composition of his remedy as soon as possible. The hope was expressed that by the modifications and improvements suggested by other workers the poisonous element might be eliminated from the preparation without injury to its active principle.

RUNSIA.

Experingnts with Koch's remedy were begun in the Institute of Experimental Medicine on November $23 \mathrm{rd}$, and a report of the first results obtained was published in the st. Petersburger med. Wochenschrift of December 13 th by Drs. F. Sperck, W Kudrewezki, and D. Kamenski. They were similar to those reported by other observers. On December 28 th Dr. Lebedew began a series of clinical experiments, in the Red Cross Lazaretto at Jalta, with Koch's fluid, which had been brought 
from Berlin a fortnight previously by himself and Dr. Gurian, who had gone there as delegates from the Jalta Medical Society. In consequence of the decision of the Medical Council, however, the lymph could not be used till permission had been obtained from the Minister of the Interior. The medical profession at Jalta has passed a resolution that it is desirable that a special institution for the carrying out of Koch's treatment should be established in the town. The remedy has also been tried in the City Hospital at Riga in cases of tuberculosis of the skin, larynx, and joints.

The first death under Koch's treatment which has occurred in Russia is reported from Simferopol (Taurida). The patient a district magistrate named Kowalewski, is said to have died after one injection. Nothing, however, is said as to the condition in which he was before the remedy was tried.

DR. KOCH AND THE GERMAN GOVERNMENT. A WELL-INFORMED correspondent writes:-During the last fortnight various rumours have been telegraphed from Berlin as to the arrangements made, or about to be made, between the German Government and Professor Koch with regard to the future production of his remedy for tuberculosis, and it must be admitted that these rumours have been of a somewhat disquieting character. It has been said that Dr. Koch, and each of his assistants, had accepted a large immediate payment, and that they were to receive a royalty upon all sales in the future. Thus stated, the arrangement, it must be admitted, would partake far too much of the commercial transaction to be agreeable to the traditions of the medical profession, or the customs of men of science. It is, however, easy to give an unfavourable complexion to a transaction really of an honourable nature by inverting the steps by which the final results have been obtained and so misrepresenting their character. It may be well to recall the circumstances under which the lymph has been discovered, and the position of Dr. Koch in relation to the German Govermment. 1)r. Koch has been for many years the director of the Hygienic Laboratory in Berlin. This laboratory is a Govermment institution, maintained by the Educational Department of the German Government, and Dr. Koch, as its director, has been an oflicer of that department. All the earlier experiments for the discovery of the now famous lymph were conducted in Dr. Koch's own laboratory in the Hycrenic Institute, and there the observations upon guinea-pigs and other animals, which emboldened Dr. Koch to proceed to inoculate human beings, were made. The laboratory, however, presented no facilities for making these investigations upon human beings, and Dr. Koch holds no official position with regard to any of the Berlin hospitals. He therefore found himself in a practical dilemma, inasmuch as if he were to make his experiments in a public hospital it was feared that the premature and eager discussion of incomplete observations and immature results might easily tend to interfere materially with the investigations and to produce evil results. Dr. Koch consequently liired a private house at his own expense, and obtained the assistance of two gentlemen with whom he had private acquaintance-Dr. Libhert\%, an old schoolfellow, and Dr. Pfuhl, his own son-in-law. The lymph was prepared in considerable quantities in this private house by these two gentlemen under Dr. Koch's supervision, and the earliest injections in man were made in the private lospitals of Drs. Cornet and Levy. It soon became evident, however, that the interest, both among the general public and in the medical profession, was too keen to permit of the continuance of the investigation upon these lines; and Dr. Koch, acting on the advice, or perhaps it might be correct to say upon the instructions, of Herr von Gossler, the Minister of Education, published the now famous preliminary paper, and distributed the lymph to certain of the hospitals in Berlin. Meanwhile, the manufacture of the lymph was carried on in the private house hy Dr. Koch and his two personal private assistants. Recently this arrangement has ceased; the house in which the lymph is manufactured has been taken over by the Education Department of the German Government, and Drs. Pfuhl and Libbertz have become officers of that department. The Koch Institute, which the German Government are now erecting, will consist of two parts-a laboratory and a clinical department containing 150 beds. The clinical department will probably be under the direction of Professor Brieger. The observation and treatment of the patients received into it, it is hoped, will afford in the future opportunities for Dr. Koch to prosecute his studies with regard not only to tuberculous diseases, but to tetanus, diphtheria, and typhoid fever. In this way the inconvenience which has arisen from his having no clinical wards of his own will be avoided.

In the laboratory bacteriological investigations will be carried on, and at the earliest possible date the laboratory for the preparation of the anti-tuberculous liquid will be transferred to this department of the Koch Institute. The director of this bacteriological department has not yet been appointed, but the whole institute will be under the general direction of Dr. Koch, who will remain an officer of the Education Department. It is probable that the German Government will offer to Dr. Koch some recognition of the great services he has rendered while acting as a German official, such as was voted to Jenner for his services in a cognate research, and more recently to Pasteur, in France. Large national awards have repeatedly been made to successful generals in Germany and in other countries, and it is felt that there is no reason why a man of science, who has worked for the relief of human suffering, should hesitate to accept a reward which the destroyers of men have never felt the least difficulty in receiving. As to the further rumour that Dr. Koch and his assistants may receive a payment as it were by results in the future, it may be hoped that this rumour is unfounded. Anything like the sale of a secret or the paying of royalties on a remedy would be contrary to the Hippocratic tradition.

REPORTS OF MEDICAL OFFICERS OF HEALTH.

Maidstone (Population, 32,785).-The Etiology of Diphtheria : Influence of Insanitary Conditions of Houses and Soil: Level of Subsoil Water an Important Factor.--Except for a serious prevalence of diphtheria the year $\mathbf{1 8 8 9}$ was uneventful, and a remarkably low death-rate $(13.72$ per 1,000$)$ was recorded. So serious was the diphtheria epidemic that no fewer than 29 deaths out of 99 cases were caused by it. Such a large mortality naturally gave rise to considerable anxiety in the town. The whole circumstances of the outbreak were very minutely investigated by I)r. Matthew Adams, the medical officer of health, and his special report on the subject is a most interesting appendix to his last annual report. It is not possible in a brief notice to enumerate all the points raised by Dr. Adams, and the circumstances by which he arrives at his conclusions. He believes, however, that the nearest approach to the discovery of a fundamental cause is to be found in the insanitary conditions of the houses or their surroundings, more particularly in the foul states of the house drains, etc., soil adjacent thereto, and the noxious effluvia escaping by the sewer ventilators, and given off from the retained sewage. He argues that "granted that diphtheria is due to a specific microbe whose natural habitat is polluted surface soil and similar situations, its propagation in the soil is due to suitable meteorological conditions, and its reception, in the animal body at least, is favoured by certain coincident pathological states, and perhaps other life-conditions of environemnt special to the organism itself, determining its development and activity." Alteration, therefore, in the level of the subsoil water is, in the opinion of Dr. Adams, a material factor in diphtheria outbreaks.

THe Woolwich Local Board of Health have agreed to purchase for $£ 2,000$ a plot of freehold land for the erection of baths and washhouses. 